Open Access

\title{
Stenting of the Left Main Coronary Artery in a Patient With Takayasu's Arteritis
}

\author{
Hyo Keun Lee, MD, June Namgung, MD, Won-Ho Choi, MD, Hyunmin Choe, MD, \\ Sung Uk Kwon, MD, Joon Hyung Doh, MD, Sung Yun Lee, MD and Won Ro Lee, MD \\ Department of Internal Medicine, Vision 21 Cardiac and Vascular Center, Inje University, Ilsan Paik Hospital, Goyang, Korea
}

\begin{abstract}
Management of Takayasu's arteritis of the left main coronary artery (LMCA) is difficult because of the possibility of restenosis. Clinically significant stenotic lesions must be considered anatomical correlation. Many studies have reported that the management of stenotic lesions of the LMCA with endoluminal stenting and balloon angioplasty and de-novo stenting is safe and effective for patients with Takayasu's arteritis. We report the case of a patient with Takayasu's arteritis of the LMCA. The patient had undergone two consecutive percutaneous coronary interventions because of recurrent restenosis of in-stent lesions, and eventually underwent coronary artery bypass graft (CABG) surgery for myocardial infarction in the same lesion. We suggested treatment with CABG because the pathophysiology of Takayasu's arteritis is different from that of atherosclerotic stenosis.

(Korean Circ J 2011;41:34-37)
\end{abstract}

KEY WORDS: Takayasu arteritis; Coronary artery disease; Percutaneous transluminal coronary angioplasty.

\section{Introduction}

Takayasu's arteritis is an idiopathic vasculitis of the large vessel involving the aorta and the subclavian and innominate arteritis. ${ }^{1-3)}$ Takayasu's arteritis is one of the most common causes of hypertension in adolescents, and differences in blood pressures between both arms is a common sign of Takayasu's arteritis in adults. Clinical deterioration caused by severe fixed stenosis is a challenging issue because of restenosis of in-stent lesions. ${ }^{45)}$ A previous study has suggested that endoluminal stenting may be an alternative treatment to coronary artery bypass graft (CABG) surgery for patients with coronary artery stenosis due to active Takayasu's arteritis. ${ }^{6}$ Some studies have reported that Takayasu's arteritis with left main coronary ar-

Received: December 28, 2009

Revision Received: March 15, 2010

Accepted: May 24, 2010

Correspondence: June Namgung, MD, Department of Internal Medicine, Vision 21 Cardiac and Vascular Center, Ilsan Paik Hospital, Inje University, 2240 Daehwa-dong, Ilsanseo-gu, Goyang 411-706, Korea

Tel: 82-31-910-7834, Fax: 82-31-910-7829

E-mail: medngj@gmail.com

- The authors have no financial conflicts of interest.

$@$ This is an Open Access article distributed under the terms of the Creative Commons Attribution Non-Commercial License (http://creativecommons.org/licenses/by-nc/3.0) which permits unrestricted non-commercial use, distribution, and reproduction in any medium, provided the original work is properly cited. tery (LMCA) stenosis is successfully treated with the use of a sirolimus-eluting stent and a paclitaxel-eluting stent after repeated in-stent restenosis following bare metal stenting. ${ }^{4) 7-9)}$ However, we report here the case of a 54-year-old woman with recurrent restenosis of an in-stent lesion followed by myocardial infarction, who eventually underwent CABG.

\section{Case}

A 54-year-old woman presented with recently developed dyspnea on exertion. She was previously healthy and had no symptoms except for exertional dyspnea. However, a discrepancy in blood pressure measurements between the right and left arms was noted during a routine examination (right arm: 70/40 mmHg; left arm: 130/80 mmHg). Bruit was audible in the right subclavian area, and right radial pulsation was not palpable. On admission, we performed peripheral angiography and coronary angiography. The peripheral angiography revealed total occlusion of the right subclavian artery (Fig. 1). The coronary angiography showed a $60 \%$ focal stenosis in the ostium of the LMCA (Fig. 2A).

The LMCA was engaged with a 6 Fr guiding catheter via the femoral artery, and a 0.014 inch Hi-torque Whisper $\mathrm{MS}^{\mathrm{TM}} \mathrm{gu}-$ idewire (Guidant, Santa Clara, CA, USA) was able to cross the lesion without difficulty. We predilated the lesion with an ART 


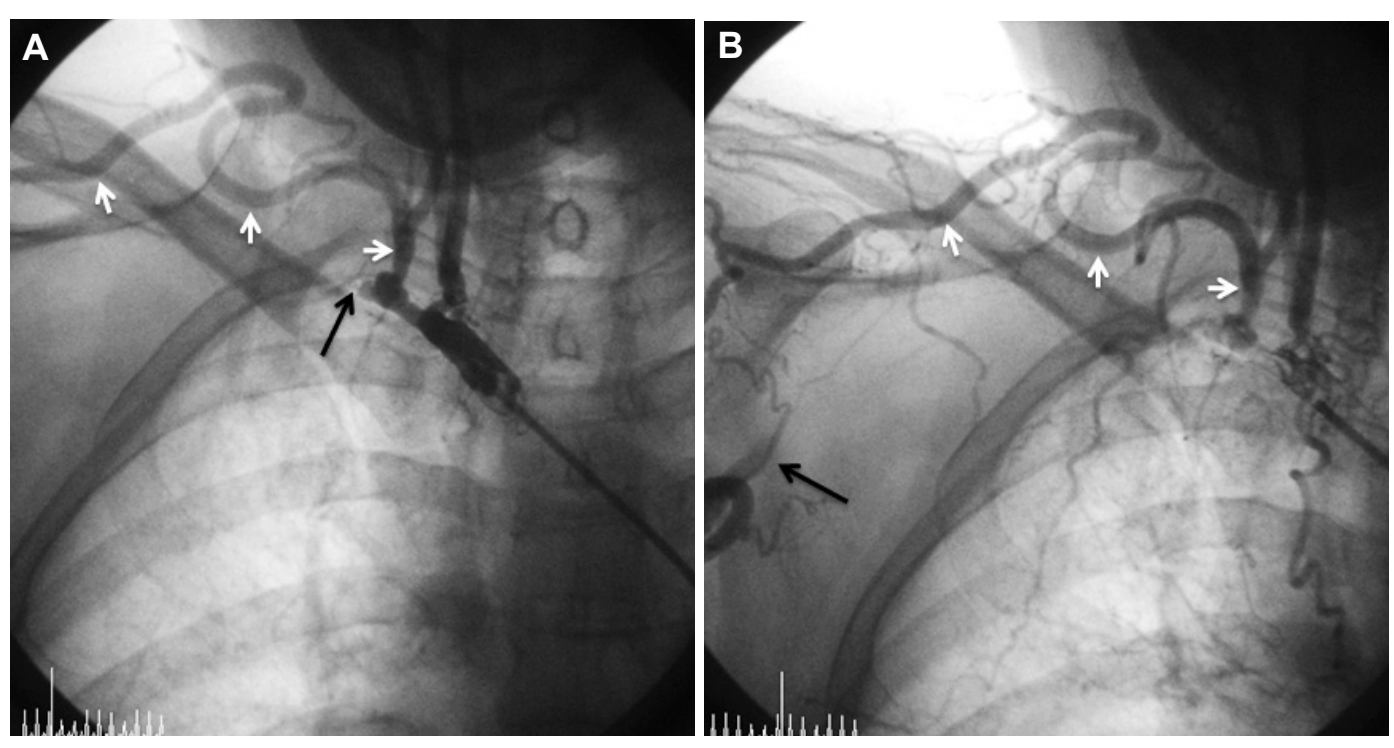

Fig. 1. Angiography of the right subclavian artery show total occlusion (black arrow) near the origin and marked dilation of the collateral artery (white arrows) originating from the thyrocervical trunk in the early phase (A) and a reconstituted axillary artery (black arrow) via dilated collaterals (white arrow) in later phase (B).
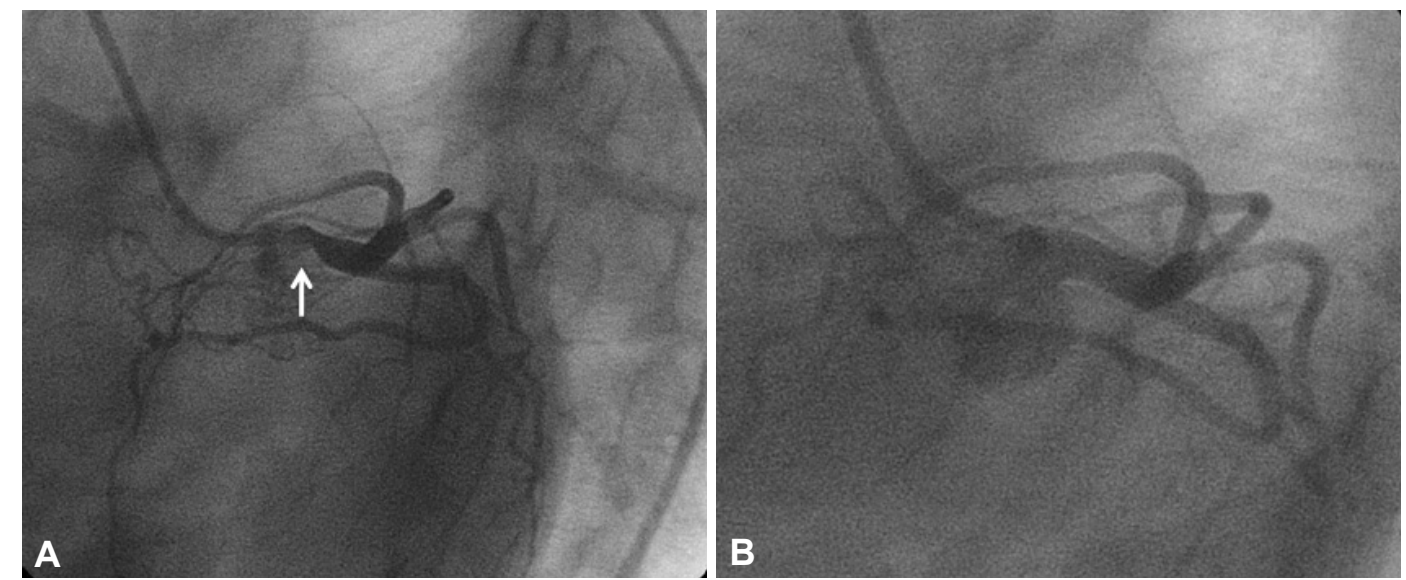

Fig. 2. Angiography of the left coronary angiography show focal stenosis in the ostium of left main coronary artery (A) and a paclitaxel-eluting stent deployed in the ostium of the left main coronary artery (B).

$2.5 \times 20 \mathrm{~mm}$ ART ${ }^{\mathrm{TM}}$ balloon (AMG, Raesfeld-Erle, Germany) up to $8 \mathrm{~atm}$ and then deployed a PICO ${ }^{\mathrm{TM}} 4.0 \times 10 \mathrm{~mm}$ stent (AMG) at a maximum of $20 \mathrm{~atm}$. The angiographic result was good (Fig. 2B). The patient was discharged the next day and took aspirin and clopidogrel. Anti-inflammatory agents were not prescribed to the patient because the erythrocyte sedimentation rate and the C-reactive protein concentration were within normal ranges at the time of discharge. Although the patient had been asymptomatic over the next 3 months, a followup coronary angiography was performed at 3 months because many cases of coronary artery restenosis in Takayasu's arteritis occur without detectable cardiac symptoms. An intravascular ultrasound was also performed at this time, which showed a 75\% segmental stenosis in the proximal portion of the in-stent lesion area; however, the other sites had normal coronary vascular features (Fig. 3A). We performed a percutaneous coronary intervention (PCI) at the site of the in-stent resteno- sis lesion and used a TAXUS ${ }^{\text {TM }} 3.5 \times 12 \mathrm{~mm}$ stent (Boston Scientific, Boston, MA, USA) at a maximum of $22 \mathrm{~atm}$; a good angiographic result was obtained (Fig. 3B). The patient took medications, including aspirin, clopidogrel, and cilostazol. Three months later, she experienced resting chest pain and dyspnea. A chest X-ray showed pulmonary edema in both lower lung fields. An electrocardiogram showed an ST depression and a $T$ wave inversion on precordial leads, and the concentration of the cardiac enzyme creatine kinase was elevated $(38.11 \mathrm{ng} / \mathrm{mL})$. The patient became hypotensive (blood pressure, right arm: $75 / 50 \mathrm{mmHg}$ ). Echocardiography indicated global hypokinesia, with a $40 \%$ ejection fraction. A follow-up coronary angiography revealed tight stenosis greater than $90 \%$ in the distal portion of the in-stent site (Fig. 4). On the basis of these findings, we performed an emergency CABG, which was successful. One year later, the patient underwent coronary angiography. No new stenotic lesions or graft stenosis was observed. 

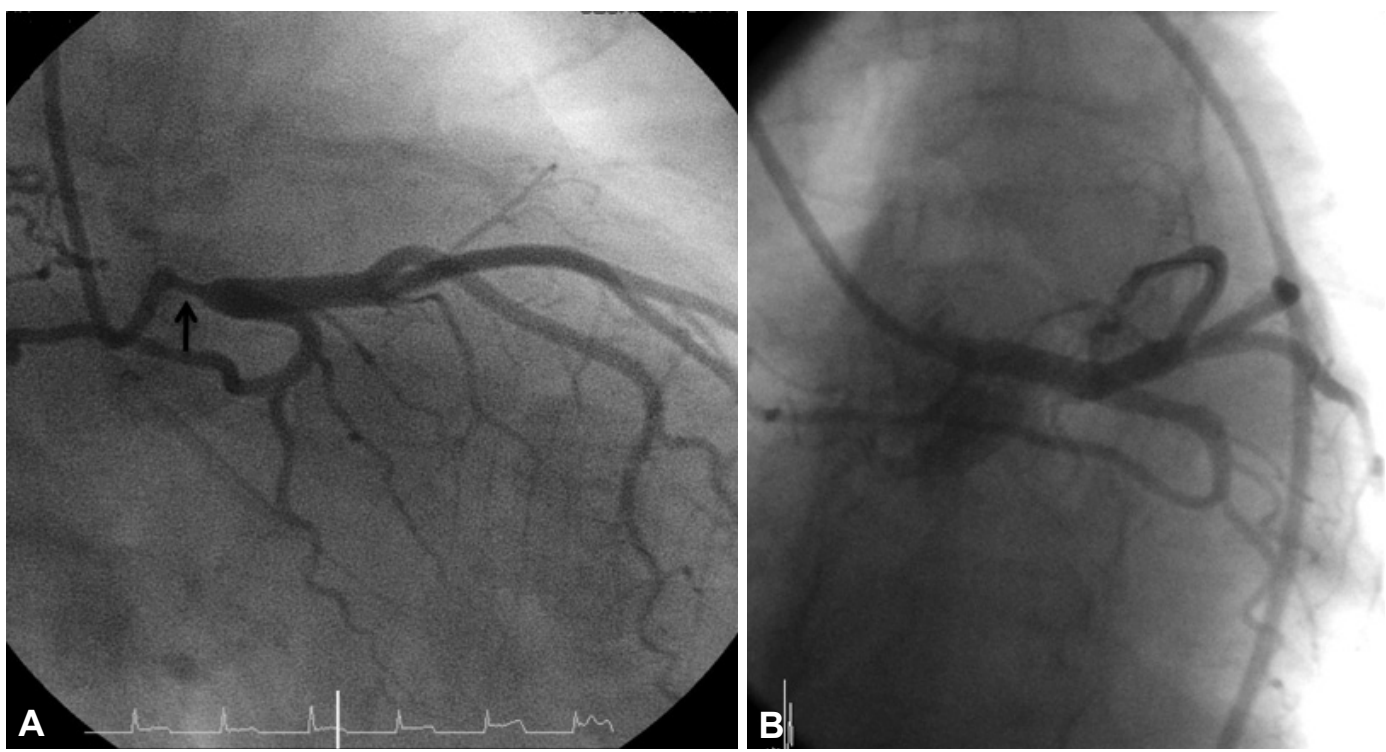

Fig. 3. A follow-up coronary angiography shows $75 \%$ segmental stenosis in the proximal portion of the in-stent lesion area (A) and another paclitaxel-eluting stent (TAXUS ${ }^{\mathrm{TM}}$ ) deployed in the in-stent lesion (B).

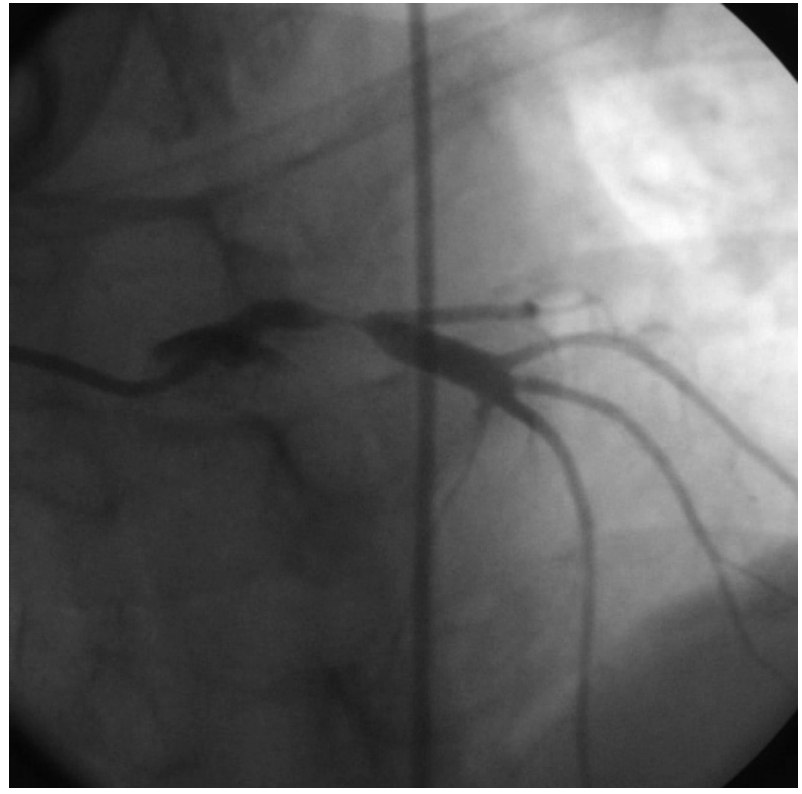

Fig. 4. Coronary angiography shows tight insent restenosis after second intervention in the ostium of the left main coronary artery.

\section{Discussion}

Takayasu's arteritis is an idiopathic vasculitis of the large vessel that affects the aorta and its major branches. ${ }^{1-3) 10)}$ The coronary artery is a rare site of Takayasu's arteritis, reportedly occurring in only $6-19 \%$ of cases; the most common site of coronary stenosis is the ostium of the LMCA. ${ }^{511112)}$

Clinical manifestations of Takayasu's arteritis of the coronary artery include angina pectoris and myocardial infarction. ${ }^{13-15)}$ The recommended treatment of Takayasu's arteritis with LMCA stenosis with is percutaneous angioplasty or surgery. For poor surgical candidates or patients who prefer a nonsurgical treatment, $\mathrm{PCI}$ may be a more beneficial revascu- larization strategy than $\mathrm{CABG} .{ }^{4) 1116)}$ Some investigators have reported that drug-eluting stents are more efficacious than are bare-metal stents. ${ }^{57-9)}$ For example, many studies recently reported a lower incidence of restenosis in the coronary artery with the use of drug-eluting stents than with bare-metal stents. Although various strategies have been used to prevent instent restenosis, restenosis is still a problem. In our patient, restenosis was observed in the in-stent lesion after consecutive coronary angioplasties.

We deployed a drug-eluting stent in the LMCA. However, in-stent restenosis occurred, and the patient was admitted to the hospital because of myocardial infarction. Matsubara et al. ${ }^{11)}$ classified coronary lesions on the basis of pathological features and reported stenosis or occlusion of the ostia. The extension of the inflammatory process of the intimal proliferation and contraction of the fibrotic media and adventitia cause luminal narrowing. Thus, drug-eluting stents may provide effective results through an antiproliferative effect against vascular smooth muscle cells. However, because of differences in the etiologies and in the inflammatory/immune-mediated processes of atherosclerosis and Takayasu's arteritis, the use of coronary stenting-which is effective for the treatment of atherosclerotic stenosis lesions-may not be safe or effective for the treatment of Takayasu's arteritis. In a previous study, favorable results of percutaneous stent implantation for LMCA stenosis in Takayasu's arteritis were reported. ${ }^{57-9)}$

However, previous studies showing favorable results had limited success in Takayasu's arteritis with good patency because of short and intermediate follow-up times after percutaneous stent implantation for LMCA stenosis. ${ }^{5-7)(77) 18}$ Son et al. ${ }^{6)}$ refer to stent insertion as a therapy used to postpone CABG. The lesions most commonly affected by Takayasu's arteritis are the ostial or proximal coronary segments, which pose 
anatomic challenges for the performance of PCI. Surgical treatments are often more suitable for patients with Takayasu's arteritis because of the pathophysiologic characteristics of this disease. Sakai et al. ${ }^{8)}$ reported that both short-term and longterm follow-up are required to evaluate the effects of drug-eluting stents on Takayasu's arteritis. Son et al. ${ }^{6}$ suggest that endoluminal stenting and rotational atherectomy may be useful treatments for postponing CABG in patients with coronary artery stenosis due to active Takayasu's arteritis.

For our patient, we recommended CABG for the treatment of Takayasu's arteritis involving the LMCA because the pathophysiology of this condition is different from that of atherosclerotic stenosis.

\section{REFERENCES}

1) Lupi-Herrera E, Sánchez-Torres G, Marcushamer J, Mispireta J, Horwitz S, Vela JE. Takayasu arteritis: clinical study of 107 cases. Am Heart J 1977;93:94-103.

2) Hall S, Barr W, Lie JT, Stanson AW, Kazmier FJ, Hunder GG. Takayasu arteritis: a study of 32 North America patients. Medicine 1985;64: 89-99.

3) Bulut S, Al Hashimin HM, Verheugt FW. Left main stem disease in a patient with Takayasu's arteritis. Neth Heart J 2007;15:260-2.

4) Endo M, Tomizawa $Y$, Nishida $H$, et al. Angiographic findings and surgical treatments of coronary artery involvement in Takayasu arteritis. J Thorac Cardiovasc Surg 2003; 125:570-7.

5) Furukawa Y, Tamura T, Toma M, et al. Sirolimus-eluting stent for instent restenosis of left main coronary artery in Takayasu arteritis. Circ $J$ 2005; 69:752-5.

6) Son JW, Koh KK, Dang Q, Choi IS, Shin EK. Recurrent restenosis following stent and rotational atherectomy of coronary artery stenosis in
Takayasu's arteritis. Int J Cardiol 1998;65:295-300.

7) Kang WC, Han SH, Ahn TH, Shin EK. Successful management of left main coronary artery stenosis with a paclitaxel-eluting stent in Takayasu's arteritis. Int J Cardiol 2006;108:120-3.

8) Sakai H, Oyama H, Kishimoto N, Takahashi M, Urasawa K, Tsutsui H. Revascularization of malignant coronary instent restenosis resulting from Takayasu's arteritis using sirolimus-eluting stent. Int Heart J 2006; 47:795-801.

9) Amir O, Kar B, Civitello AB, Palanichamy N, Shakir A, Delgado RM 3rd. Unprotected left main stent placement in a patient with Takayasu's arteritis. Tex Heart Inst $J$ 2006;33:253-5.

10) Kim KC, Park JI, Lee J, et al. Clinical characteristics of Takayasu's arteritis. Korean Circ J 2001;31:1106-16.

11) Matsubara $O$, Kuwata $T$, Nemoto $T$, Kasuga $T$, Numano F. Coronary artery lesions in Takayasu's arteritis. Heart Vessels Suppl 1992;7;26-31.

12) Park JH, Han MC, Kim SH, Oh BH, Park YB, Seo JD. Takayasu arteritis: angiographic findings and results of angioplasty. AJR Am J Roentgenol 1989;153:1069-74.

13) Trazzera S, Colasacco J, Ong L. Takayasu arteritis with unstable angina and aortic insufficiency. Am Heart J 1995;130:1122-4.

14) Antelmi I, Magalhães L, Caramelli B, et al. Salvage coronary angioplasty in a young patient with Takayasu arteritis and myocardial infarction. Arq Bras Cardiol 1993;60:37-8.

15) Kang KT, Jeong MH, Jeong WK, et al. Long-term clinical follow-up in a case of Takayasu's arteritis involving the ostium of left coronary artery after ostioplasty. Korean Circ J 2001;31:246-50.

16) Punamiya K, Bates ER, Shea MJ, Muller DW. Endoluminal stenting for unprotected left main stenosis in Takayasu's arteritis. Cathet Cardiovasc Diagn 1997; 40:272-5.

17) Kang WC, Han SH, Oh KJ, Ahn TH, Shin EK. Implantation of a drugeluting for the coronary artery stenosis of Takayasu arteritis: de novo and in-stent restenosis. Circulation 2006;113:e735-7.

18) Park JS, Lee HC, Lee SK, et al. Takayasu's arteritis involving the ostia of three large coronary arteries. Korean Circ J 2009;39:551-5. 